\title{
Transforming Learning-Empowering Children through Multiple Intelligences
}

\author{
Venkateshwar Rao $\mathrm{D}^{1 *}$
}

\section{ABSTRACT}

The purpose of this study is to evolve a cooperative learning strategy using teaching-learning activities prepared according to Multiple Intelligences Theory and study the impact on scholastic achievement of students. The study has been carried out on 6th grade students who did not show any improvement in an intervention programme especially with respect to scholastic achievement. Data was collected from 16 students of 6th grade by following purposive sampling technique. Data was subjected to statistical analysis by using mean and t- test. The findings indicate that when cooperative learning opportunities are combined in the curriculum by using Multiple Intelligences theory, students' scholastic achievement in various subjects will be improved. It has been recommended to follow the same teaching-learning approach to improve the scholastic achievement of students at school level.

Keywords: Multiple Intelligences, Scholastic Achievement, Cooperative Learning, Teaching Learning Activities

People have many individual differences that distinguish them from others. One of these differences is intelligence. The concept of intelligence has been employed in varied ways over the centuries. There is no universal definition for intelligence. Different psychologists have defined intelligence in different ways. For example: Terman defined intelligence as "the ability of an individual to carry out abstract thinking". According to Wechsler intelligence is "the global capacity of the individual to act purposefully, think logically and deal effectively with the environment"' (Parameshwaran \& Beena, 2002). Thorndike defined intelligence as "the power of good responses from the point of view of truth or fact”. (Mangal, 2004).Similarly the concept of measuring intelligence attracted various methodologies in research studies.

Since, there is no consensus on the definition and measurement of intelligence, many theories has been developed. Spearman's two factor theory, E.L. Thorndike's group factor theory and

\footnotetext{
${ }^{1}$ ICSSR Post-Doctoral Fellow, Dept. of Psychology, Osmania University, Hyderabad, India *Responding Author

(C) 2016, V Rao; licensee IJIP. This is an Open Access Research distributed under the terms of the Creative Commons Attribution License (http://creativecommons.org/licenses/by/2.0), which permits unrestricted use, distribution, and reproduction in any Medium, provided the original work is properly cited.
} 


\section{Transforming Learning-Empowering Children through Multiple Intelligences}

Howard Gardner's multiple intelligences theory can be listed as some examples (Smith, 2002, Smith, 2008 \&Smith, et al., 2003). Gardner opposed the notion of a unitary Intelligence Quotient (IQ) and proposed that intelligence be thought of as a wide range of human capabilities.

\section{Multiple intelligences theory}

Gardner's first full length statement of the theory of multiple intelligences was published in 1983 in the book titled "Frames of mind: The Theory of multiple intelligences". Initially Gardner, (1983) defined intelligence as "the ability to solve problems or to create products that are valued within one or more cultural settings". Revising his definition in 1999, he defined intelligence as 'a bio psychological potential to process information that can be activated in a cultural setting to solve problems or create products that are of value in a culture' (Gardner, 1999, Gardner \& Hutch,1999).

\section{Teaching-learning process - a major concern and challenge}

In providing schooling facilities to all children in India, considerable progress has been achieved after independence. But quality of learning remains an area of major concern and challenge. Ministry of Human Resource Development, Government of India constituted a committee in November 2015 to formulate a draft national education policy. The committee observed poor learning out comes as the biggest challenge facing Indian education on the basis of various research studies which show a decline in learning levels (Government of India, 2016).Studies undertaken by the government and various private organizations in primary and elementary classes are observed poor learning levels (ASER, 2015: Education Initiatives, 2010; Pratham, 2005-2010; NCERT, 2008).

According to Children's Learning Acceleration for Sustainability Andhra Pradesh (CLAPS) an initiative that aims to improve learning levels in all areas of the primary school curriculum, about 35 percent of children are unable to read and write and perform fundamental mathematical operations. Andhra Pradesh State Curriculum Framework- 2011(State Council of Educational Research and Training, 2011) included teaching-learning process as one of the major concerns and challenges. It says "Children learn by doing and observing at elementary stage which requires meaningful activities/projects in every subject and teacher acting as facilitator. Most of the schools show no evidence of such practice except lecture mode, reading text books Para by Para and explaining and asking children to copy down answers from the text books.

According to many research studies the rich interactions between teacher-pupil, pupil-pupil and pupil and learning material are missing in classrooms.

National Curriculum Framework, 2005 observed that "much of our learning is still individual based (although not individualized!). The teacher is seen as transmitting knowledge, which is usually confused with information, to children and organizing experiences in order to help 


\section{Transforming Learning-Empowering Children through Multiple Intelligences}

children learn. But interaction with teachers, with peers, as well as those who are older and younger can open up many more rich learning possibilities. Learning in the company of others is a process of interacting with each other. It is also through the learning task at hand (National Council of Educational Research and Training, 2005).According to various research studies cooperative learning strategies facilitates better learning outcomes at school level. According to Ediger, M (1998) to optimize instruction we should help students to work effectively with others in collaborative situations. The present study used multiple intelligences approach as a cooperative learning strategy.

The purpose of Multiple Intelligences theory is not to label or exclude individuals. The purpose is to promote success for all learners. This can be achieved by allowing the learners to choose different paths to learn a task. (McKenzie, 2009). Multiple intelligences theory allows such type of teaching-learning activities at school level. So the investigator designed the intervention programme by integrating multiple intelligences to improve the scholastic performance of students. The results (Table no. 1) indicate that the performance of the students improved significantly after the intervention.

\section{Objectives}

1. To identify Multiple Intelligences profiles of poor performers of $6^{\text {th }}$ grade.

2. To study the impact of teaching-learning activities prepared according to the Multiple Intelligences Theory as a cooperative learning strategy on academic achievement of poor performers.

3. To compare the mean achievement scores of scholastic achievement test (pre and post intervention).

\section{Hypotheses}

1. Cooperative learning strategy using Teaching-learning activities prepared according to Multiple Intelligences Theory helps to improve scholastic performance of $6^{\text {th }}$ grade students.

\section{METHOD}

\section{Sample}

The sample of the study comprised of 16 students of $6^{\text {th }}$ grade. The sample was drawn from 208 sixth grade students who have gone through an intervention and showed poor performance even after the intervention.

\section{Research Tools}

Students Personal Data Schedule: It was developed by the investigator to gather information related to gender, community, family income etc. 
Multiple Intelligences Survey (MIS): MIS was developed by McKenzie. It consists of multiple intelligences domains with 10 statements for each domain. The participants have to place 1 next to each statement if it accurately describes them. If the participants do not identify with a statement they have to leave the space blank.

\section{Procedure}

Research was conducted after taking permission from the school authorities and obtaining consent from the students. After fixing the tentative time schedule for the study, data were collected before and after intervention.

In the first step the investigator identified 16 poor performers of $6^{\text {th }}$ grade on the basis of their poor scholastic performance (score of less than 45\%) in the scholastic achievement test of a research study. In the second step MIS was administered. Students Multiple Intelligences profiles were prepared on the basis of MIS scores and discussed with them. They were advised to build their learning process on the basis of their strengths based on multiple intelligences profiles and improve in the weak areas. In the third step the investigator facilitated the cooperative learning through Multiple Intelligences (MI) theory approach for a span of 9 weeks. The investigator facilitated the cooperative learning among students.

The following diagram helps to understand the procedure adopted by the investigator to facilitate cooperative learning through MI approach among students.

\section{Co-operative learning through MI approach: Diagrammatical representation}

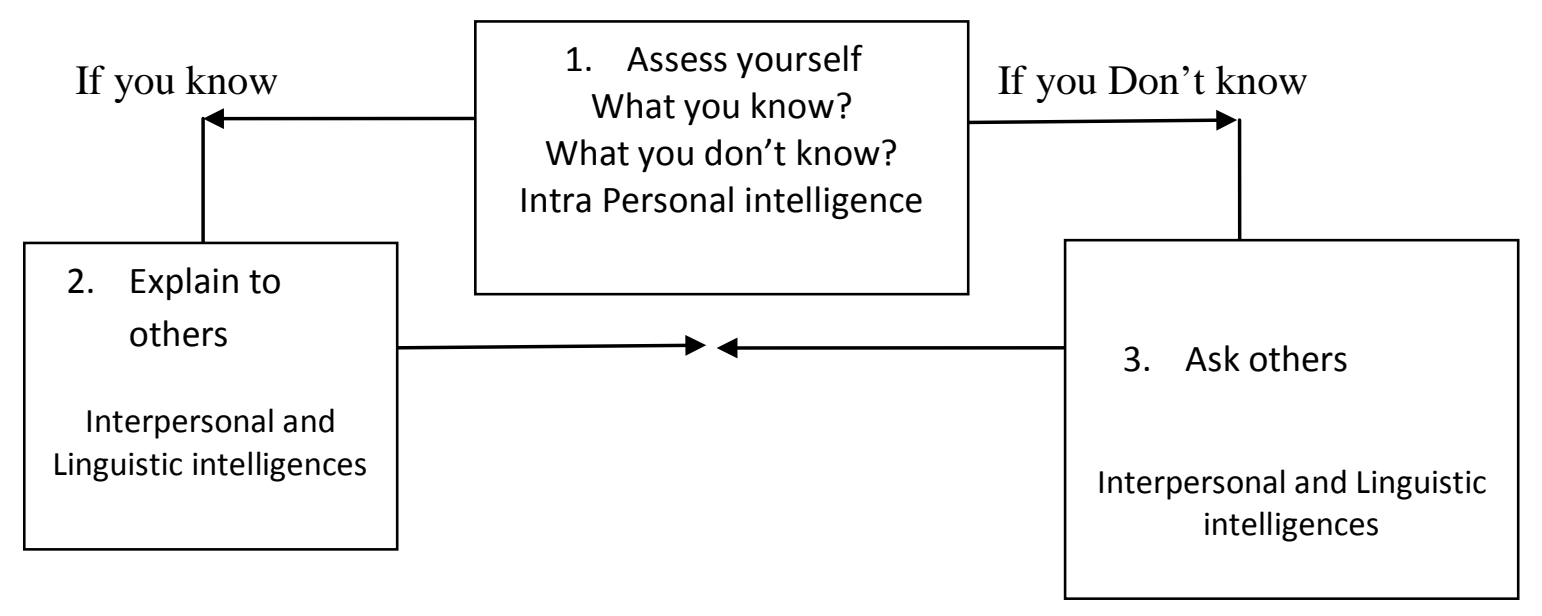

Figure No. 1 showing cooperative learning through MI approach.

The above figure No. 1, describes the procedure adopted for cooperative learning through MI approach. After self assessment student asks others for explanation. If they know a concept then they explain to others by using the following methods. 
- $\quad$ Using charts (Spatial intelligence)

- $\quad$ Using songs (Musical intelligence)

- $\quad$ Using relationships (Logical intelligence)

- $\quad$ Using real world applications (Naturalistic intelligence)

- $\quad$ Using physical objects (Body -Kinesthetic intelligence)

After the intervention the students performance on the basis of scholastic achievement test marks (provided by the school) was recorded and analyzed

\section{Data Analysis}

Data was analyzed by using statistical techniques mean and ' $\mathrm{t}$ ' test.

\section{Ethical issues followed}

A written consent was taken from the school authorities to conduct the study. Similarly an oral consent from the students was taken. The freedom to withdraw from the study at any stage was given to school authorities and students. Confidentiality of the data was assured. Finally data was collected from the students with the help of research tools (self administered questionnaires).

\section{RESULTS}

\section{Sample}

Out of 16 students 7 are boys (44\%) and 9 are girls (56\%). Community wise BC's are 75\% and SC's are $12.5 \%$ and OC are $12.5 \%$. 56\% of the families belong to income group of Rs. 5,000 Rs. 10,000 and $38 \%$ families up to Rs. 5,000 income per month. $6 \%$ of the families belong to income of above Rs. 10,000 per month.

\section{Table no: 1, Showing the mean scores of students Multiple Intelligences}

\begin{tabular}{|l|l|l|}
\hline Intelligence & Mean score & Rank \\
\hline Naturalist Intelligence & 8.63 & 1 \\
\hline Bodily-Kinesthetic Intelligence & 7.94 & 2.5 \\
\hline Interpersonal Intelligence & 7.94 & 2.5 \\
\hline Logical Mathematical Intelligence & 7.69 & 4 \\
\hline Intra personal Intelligence & 7.38 & 5 \\
\hline Spatial Intelligence & 7.25 & 6.5 \\
\hline Musical Intelligence & 7.25 & 6.5 \\
\hline Linguistic Intelligence & 6.38 & 8 \\
\hline
\end{tabular}

From the above table no: 1 mean score of students Multiple Intelligences' ranked from 1 to 8 . The highest mean score (8.63) was on Naturalist Intelligence. The next intelligences with highest mean score of 7.94 are Bodily Kinesthetic Intelligence and Interpersonal Intelligences. Ranked number 4 is Logical Mathematical Intelligence with a mean score of 7.69 and number 5 is

(C) The International Journal of Indian Psychology, ISSN 2348-5396 (e)| ISSN: 2349-3429 (p) | 80 
Intrapersonal Intelligence with a mean score of 7.38. The next intelligences with a mean score of 6.5 are Spatial and Musical Intelligence. Ranked number 8 is Linguistic Intelligence with a mean score of 6.38 .

Table No: 2, Showing Comparative performance of students' (Scholastic Achievement Test marks) (N: 16)

*Significant at 0.01 level.

\begin{tabular}{|c|c|c|c|c|c|}
\hline Subject & & $\mathbf{N}$ & Mean & SD & 't' value \\
\hline \multirow[t]{2}{*}{ Mathematics } & Pre-Test & 16 & 44.6 & 16.4 & \multirow{2}{*}{$11^{*}$} \\
\hline & Post-Test & 16 & 64.9 & 14.6 & \\
\hline \multirow[t]{2}{*}{ Science } & Pre-Test & 16 & 33.5 & 16.3 & \multirow{2}{*}{$9.7^{*}$} \\
\hline & Post-Test & 16 & 55.9 & 18.1 & \\
\hline \multirow[t]{2}{*}{ Social } & Pre-Test & 16 & 38.1 & 16.1 & \multirow{2}{*}{$13.8 *$} \\
\hline & Post-Test & 16 & 64.9 & 18.8 & \\
\hline \multirow[t]{2}{*}{ First Language } & Pre-Test & 16 & 38.4 & 18.8 & \multirow{2}{*}{$13.4^{*}$} \\
\hline & Post-Test & 16 & 63.3 & 16.5 & \\
\hline \multirow[t]{2}{*}{ Second Language } & Pre-Test & 16 & 38.4 & 16.3 & \multirow{2}{*}{$6.8^{*}$} \\
\hline & Post-Test & 16 & 59.4 & 17.5 & \\
\hline \multirow[t]{2}{*}{ English } & Pre-Test & 16 & 36.7 & 14.5 & \multirow{2}{*}{$10.7^{*}$} \\
\hline & Post-Test & 16 & 57.6 & 14.5 & \\
\hline
\end{tabular}

Table no. 2 indicates that mean scores of students before and after intervention in Mathematics are 44.6 and 64.9 respectively for the SD values of 16.4 and 14.6. Similarly the mean scores of Science and Social Studies are 33.5, 55.9 and 38.1, 64.9 respectively before and after intervention. The mean scores of first and second languages are 38.4, 63.3 and 38.4, 59.4 respectively before and after intervention. In English the mean scores are 36.7 and 57.6 respectively before and after intervention. t-values indicate that the results are significant.

\section{DISCUSSION}

To appreciate the distribution of intelligences in a class room it may be helpful to administer a multiple intelligences survey to students. McKenzie (1999) developed an inventory of multiple intelligences. According to McKenzie (2009) it is not offered as definitive measurement of a static intelligence, but as a snapshot of how students currently perceive their strengths in intelligences. This survey was not used to label or categorize students. Mc Kenzie, (2009) says "our goal should be to provide instructional opportunities that promote all intelligences. According to Gardner Linguistic and Logical- Mathematical intelligences have been typically valued in schools (Smith, 2008). Musical, Body-Kinesthetic and Spatial intelligences are usually associated with the arts. Interpersonal and intrapersonal intelligences are called as personal intelligences. 


\section{Transforming Learning-Empowering Children through Multiple Intelligences}

Gardner $(1997,1999)$ states that in the area of intelligence, no two people have exactly the same intelligences, nor in the same combination and that understanding and valuing these uniqueness and differences and utilizing them for the benefit of society is of utmost importance. It is simply an opportunity for the investigator to appreciate the unique distribution of intelligences within each of students.

The table no: 1 indicates that the highest mean score was on 'Naturalist Intelligence'. This suggests that the students have strong interest in the activities like collecting specimens from nature, planting, doing experiments about nature. It indicates that they have much knowledge of the living world and able to use that knowledge productively.

According to the mean scores, students are strong in naturalist intelligence with a mean score of 8.63 this can be interpreted in two ways. Firstly majority of the students belong to low socio economic background. According to the data, $75 \%$ are BC, $12.5 \%$ are SC and $31 \%$ are illiterate families, and $50 \%$ of parents (fathers) private employees and $56 \%$ of families are in the income group of Rs. 5, 000- Rs. 10, 000 per month which gives them more chances to explore the physical world around them. Secondly, activities such as attribute grouping, sorting etc, which stimulates this intelligence when incorporated in the teaching-learning process investigator, found that students participated actively to learn a concept.

Ranked number two with a mean score of 7.94 are Bodily-Kinesthetic Intelligence and Interpersonal Intelligence. This shows that students have more interest in activities where they make use of their body or parts of it. These include dancing, sports, games and athletics. At this age (about 11-12 years) students seem to have in exhaustible physical energy to spend in sports, games, dance etc, physical activities. It is the intelligence which is stimulated by one's physical interactions with one's environment. It is promoted through fine and gross motor activities like manipulated materials, active games and science labs. A hand on learning environment enriches this intelligence.

Investigator found that students actively participated in the hands on learning environment which was created during the research programme.

Interpersonal intelligence is stimulated by interactions with others. It requires collaborations to make sense of learning. Because of the nature of this the students who are strong in interpersonal intelligence may be labeled as 'too talkative' or 'excessively social' in the traditional classrooms Ranked number four (4) is logical mathematical intelligence. It is the intelligence which allows solving problems. It is not only the intelligence of mathematics, but of logic and reasoning. It seeks structure in the learning environment. 


\section{Transforming Learning-Empowering Children through Multiple Intelligences}

Ranked number five (5) is intrapersonal intelligence (mean score 7.38) which means that the students have the ability to gain access to understand their own inner feelings, dreams and ideas. The next intelligences which had the highest mean score was spatial intelligence and musical intelligence (Mean score 7.25). Spatial Intelligence promotes spatial reasoning through the use of graphs, charts, tables, maps, art, illustrations, puzzles, etc materials. It allows to picture ideas and solutions to problems in one's mind before trying to verbalize or put them into practice.

Musical Intelligence includes patterns, songs, poetry, instruments, environmental sounds and rhythms. By picking the patterns in various situations, one is able to make sense of environment and adopt successfully.

The next intelligence is linguistic intelligence (Mean score 6.38). It includes one's ability to express oneself orally and in written. It is ability to master a language including foreign languages.

It is worth noting in this finding that the intelligence got lowest score was linguistic intelligence with a mean score of 6.38. It appears that the students do not like activities which involve sensitivity to language. It may be because of English as medium of instruction other than their mother tongue (Telugu).

As per the results of the above table no. 3 the mean of the students after intervention is higher than the mean of the students before intervention for all the subjects. There is a significant difference in the performance of students' taught by using teaching-learning activities prepared according to the multiple intelligences theory. This is evident from the ' $t$ ' value, which is significant at 0.01 level.

Studies point out that when learning opportunities are combined in the curriculum by using 8 intelligences domains students scholastic achievement will be more (Gardner, 2006). Any system of learning needs to strengthen not one or two of intelligences but rather all types of intelligences in order to develop balanced learning skills. A student who uses a variety of intelligences to learn will be better equipped to deal with different learning challenges (Kapur, 2007).

\section{LIMITATIONS OF THE STUDY}

The present study is limited to $16,6^{\text {th }}$ grade students of Hyderabad and Rangareddy districts of Telangana State only. In order to be able to make more meaningful generalizations about the intervention future studies should focus on more heterogeneous sample (urban, semi urban and rural) of larger size. 


\section{RECOMMENDATIONS}

1. The cooperative learning strategy incorporating multiple intelligences theory helped to improve the scholastic performance of $6^{\text {th }}$ grade students. Therefore awareness and training programmes may be conducted for teachers on using multiple intelligences theory in teaching - learning process and to design curriculum and pedagogy which incorporates multiple intelligences.

2. Awareness programmes may be conducted for parents at the time of parent-teacher meetings on using multiple intelligences theory in teaching-learning process.

3. Students may be made familiar with the multiple intelligences theory and ways to incorporate it in learning different subjects, so that they can benefit in their self learning process.

\section{IMPLICATIONS}

The findings of the present study have clear implications for all the stake holders of education i.e, teachers, parents, students and school managements. There is a need to place greater emphasis on child centered teaching learning activities, such as cooperative learning strategy incorporating multiple Intelligences to improve the scholastic performance of the students.

\section{CONCLUSION}

In short the present study suggested that each person's Multiple Intelligences profile is unique and if learning opportunities are combined in the curriculum by using Multiple Intelligences theory, students' scholastic achievement showed improvement.

\section{Acknowledgments}

The author appreciates all those who participated in the study and helped to facilitate the research process.

\section{Conflict of Interests}

The author declared no conflict of interests.

\section{REFERENCES}

Ediger, M. (1998).Change and the school administrator, Education, 118(4), 44-45.

Education Initiatives, (2010). Student Learning Study. Ahmadabad: E

Gardner, H. (1983). Frames of mind: The theory of multiple intelligences. New York: Basic Books.

Gardner, H. (1997). Multiple intelligences as a partner in school improvement. Educational Leadership, 55 (1), 20-21

Gardner, H. (1999). Intelligence reframed: Multiple intelligences for the 21st Century. New York: Basic Books.

Gardner, H., \& Hatch, T. (1989).Multiple intelligences go to school: Educational implications of the theory of multiple intelligences. Educational Researcher, 18 (8), 4-9. 


\section{Transforming Learning-Empowering Children through Multiple Intelligences}

Government of India (2016). National Policy on Education. Report of the committee for evolution of new education policy New Delhi: Ministry of Human Resource and Development.

Kapur, A. (2007). Transforming schools - Empowering Children. New Delhi: Sage Publications.

Mangal, S.K. (2004). Advanced educational psychology. (2nd ed.) New Delhi: Prentice-Hall of India Private Limited.

Mckenzie, Walter. (1999). Multiple intelligences survey. Retrieved on October,20,2010 from http:/surfaquarium.com/mi/inventory.htm

Mckenzie, Walter. (2009). Multiple intelligences and instructional technology. New Delhi: Viva Books.

National Council of Educational Research and Training, (2005). National Curriculum Framework 2005. New Delhi: NCERT.

National Council of Educational Research and Training, (2008). National Achievement Survey, 2008. New Delhi: GOI-MHRD.

Parameshwaran, E.G., Beena, C. (2002). An invitation to Psychology. Hyderabad: Neelkamal Publications Pvt. Ltd.

Pratham, (2005-2010). Annual Status of Education Report (rural). Mumbai: Pratham

Smith, Edward E. et.al (2003). Atikonson \& hilgard's introduction to psychology. 14th ed.).New York: Thomson Wadsworth.

Smith, Mark K. (2002, 2008). Howard Gardner and multiple intelligences, the encyclopedia of informal education. Retrieved on January 9, 2011 from http://www.infed.org/thinkers/gardner.htm

State Council of Educational Research and Training.(2011).Andhra Pradesh state curriculum framework,2011,Hyderabad.

The Annual Status of Education Report (Rural), 2014(2015). ASER Centre, New Delhi.

How to cite this article: V Rao (2016), Transforming Learning-Empowering Children through Multiple Intelligences, International Journal of Indian Psychology, Volume 3, Issue 4, No. 74, ISSN:2348-5396 (e), ISSN:2349-3429 (p), DIP:18.01.029/20160304, ISBN:978-1-365-46362-4 